\title{
Network Analysis Can Detect Changes In Food Web Stability Produced By Bottom Trawl Fishery In Patagonia
}

\section{Funes Manuela}

Instituto de Investigaciones Marinas y Costeras (IIMYC-CONICET)

Leonardo Saravia ( $\sim$ lsaravia@campus.ungs.edu.ar)

National University of General Sarmiento

\section{Georgina Cordone}

Centro para el Estudio de Sistemas Marinos - Consejo Nacional de Investigaciones Científicas y

Técnicas (CESIMAR - CONICET)

\section{Oscar Iribarne}

Instituto de Investigaciones Marinas y Costeras (IIMYC-CONICET)

\section{David Galvan}

Centro para el Estudio de Sistemas Marinos - Consejo Nacional de Investigaciones Científicas y Técnicas (CESIMAR - CONICET)

\section{Research Article}

Keywords: Trophic interaction, Fishing impacts, trophic structure, South Western Atlantic, weighted, network analysis, topological network analysis

Posted Date: January 19th, 2022

DOI: https://doi.org/10.21203/rs.3.rs-1218284/v1

License: (c) (i) This work is licensed under a Creative Commons Attribution 4.0 International License. Read Full License 
1 Network analysis can detect changes in food web stability produced

\title{
by bottom trawl fishery in Patagonia
}

Funes Manuela ${ }^{1}$, Saravia Leonardo A. ${ }^{2,4 *}$, Cordone Georgina ${ }^{3}$, Iribarne Oscar O. ${ }^{1}$ \& Galván David E. ${ }^{3}$

1. Instituto de Investigaciones Marinas y Costeras (IIMYC-CONICET). Rodriguez Peña 4046 Nivel 1, Mar del Plata, B7602GSD. Buenos Aires, Argentina

2. Centro Austral de Investigaciones Científicas del Consejo Nacional de Investigaciones Científicas y Técnicas (CADIC-CONICET). Bernardo Houssay 200, V9410, Ushuaia. Tierra del Fuego, Argentina.

3. Centro para el Estudio de Sistemas Marinos - Consejo Nacional de Investigaciones Científicas y Técnicas (CESIMAR - CONICET). Bv. Almirante Brown 2915, U9120ACV, Puerto Madryn. Chubut, Argentina.

4. Instituto de Ciencias, Universidad Nacional de General Sarmiento, J.M. Gutierrez 1159 (1613), Los Polvorines, Buenos Aires, Argentina.

* Corresponding author: e-mail lsaravia@campus.ungs.edu.ar, ORCID https://orcid.org/0000-0002-79114398

Keywords: Trophic interaction, Fishing impacts, trophic structure, South Western Atlantic, weighted network analysis, topological network analysis

\begin{abstract}
Demersal fisheries are one of the top anthropic stressors in marine environments. In the long term, some species are more vulnerable to fishery impacts than others, which can lead to permanent changes on the food web. The trophic relationships between predator and prey constitute the food web and it represents a network of the energy channels in an ecosystem. In turn, the network structure influences ecosystem diversity and stability. The first aim of this study was to describe for the first time the food web of the San Jorge Gulf (Patagonia Argentina) with high resolution, i.e. to the species level when information is available. The San Jorge Gulf was subject to intense fisheries thus our second aim is to analyse the food web structure with and without fishery to evaluate if the bottom-trawl industrial fishery altered the network structure and stability. We used several network metrics like: mean trophic level, omnivory, modularity and quasi-sign stability. We included these metrics because they are related to stability and can be evaluated using predator diets that can weight the links between predators and prey. The network presented 165 species organized in five trophic levels. The inclusion of a fishery node adds 71 new trophic links. All weighted and unweighted
\end{abstract}


metrics showed differences between the two networks, reflecting a decrease in stability when fishery was included in the system. Thus, our results suggested a probable change of state of the system. The observed changes in species abundances since the fishery was established, could represent the state change predicted by network analysis. Our results show how changes in the stability of food webs can be used to evaluate the impacts of human activity on ecosystems.

\section{Introduction}

Fisheries are an important human activity and they can be found in almost every coastal system worldwide. ${ }^{1}$ They are an essential source of animal protein for human consumption ${ }^{2}$ and employ a quarter of a billion people. ${ }^{3}$ On the other hand, demersal fisheries are one of the top anthropic stressors in marine environments, ${ }^{4}$ capable of modifying the habitat and its biological community. ${ }^{5}$ The selectivity of the fishing gear, together with organism traits such as body size, lifespan and habits determine how vulnerable species are to fishing activity. Fisheries, in the long-term, can alter the abundance and diversity of species ${ }^{6}$ which could change trophic relationships and the trophic level of predators, ${ }^{7-9}$ modifying the structure of the ecosystem.

Fisheries can change the relative energy demands of a community ${ }^{10}$ and alterations in the fluxes configuration can lead to changes in the stability of the food web. ${ }^{11}$ Food webs characterize the trophic interactions (i.e. consumer-resource relationships) among species in an ecosystem. ${ }^{12}$ The first step in food web analysis is to reconstruct the links between species, which describe network topology. The topology or the network structure has two components: nodes (standing for the species or groups of species), and links connecting nodes that represent the ecological interactions between the species. To describe and compare food webs, a useful approach is through network metrics related to stability and resilience of the system, like the level of omnivory, ${ }^{13}$ the mean trophic level, ${ }^{14}$ modularity ${ }^{15}$ and other metrics. ${ }^{16}$ However, an accumulating body of evidence suggests that the relationship between structural properties and stability can only be understood if the strength of interactions are considered. ${ }^{17-19}$

Bottom-trawl fisheries in northern Patagonia have mainly developed since the late 70 s. $^{20}$ Main fishing targets are the Argentine hake; Merluccius hubbsi, and the Argentine red shrimp; Pleoticus muelleri, being the shrimp fishery the biggest crustacean fishery on the south occidental Atlantic in terms of abundance and revenues. ${ }^{20}$ For the past 30 years, the main fishing activity in northern Patagonia has taken place in San Jorge Gulf (SJG), a semi-enclosed basin of approximately $230 \mathrm{~km}$ of latitudinal opening and approximately $150 \mathrm{~km}$ longitudinal wide (Figure 1). SJG is a particularly productive area in Argentina's waters where the fisheries coexist with big aggregations of marine mammals and seabirds' colonies, oil extraction and touristic activity. $^{21}$ The local fish assemblage has low redundancy, where each ecological role was accomplished, on 
average, by one species. ${ }^{22}$ Likewise, it was reported that bottom trawl fishery erodes fish functional diversity, leading towards homogenization. ${ }^{22}$ In the shrimp fishery, 81 species are incidentally caught and the hake was described as "dominant" or "abundant" species in almost $60 \%$ of the catches. ${ }^{20}$ As store space is limited and shrimp is better priced than hake, the latter was also dominant in discards composition. ${ }^{20}$ Fishes, birds and crustaceans of the area were reported to feed on discards. ${ }^{23-26}$ However, how discard biomass impacts the local community remains unaddressed, and this phenomenon requires an integrated ecosystem approach, like the one offered by food web theory. ${ }^{16}$

Information on the functionality of SJG is scarce and its understanding has economic and social importance for the region. Therefore, it was set as a priority in a national research initiative aiming to promote an ecosystem based management of the resources. ${ }^{27}$ In addition to this local interest, the theoretical description of the food web structure and its modifications by anthropic stressors are a fundamental question worldwide. This study aims to achieve a high-resolved food web description of SJG and evaluate if the bottom-trawl industrial fishery alters network structure and stability.

\section{Methods}

\section{Data}

The food web of SJG was built by a systematic search of all available studies on species and diets of marine animals of the area. The nodes of the network are the species, but in cases where there was not enough taxonomic information available, these were grouped as trophospecies.

We included stomach content analysis and direct observations studies. When the diet was not reported for SJG, studies conducted at neighbour areas were used. In these cases, we included only prey items reported for SJG. Meiofauna (organisms $<1 \mathrm{~mm}$ ) and parasites were not included. After consulting more than 300 papers, 139 of them had useful information to build the SJG food web, and the resulting list of species and interactions were revised by experts who work on SJG (Supplementary table S1).

The consumer's diet composition was estimated by the percentage of the wet weight of the prey. When wet weight information was not available, the number of organisms or the frequency of occurrence was used to assign the relative contribution of each prey. When none of those metrics were available, the diet was estimated based on the relative abundance of prey items in catch records, assuming capture reflects abundance. For each predator, the sum of total diet preferences has to equal one.

To study the impact of the fishery in the SJG ecosystem, we constructed a second food web including a new node ("fishery") and new interactions. We used shrimp fisheries records to generate a list of species caught 


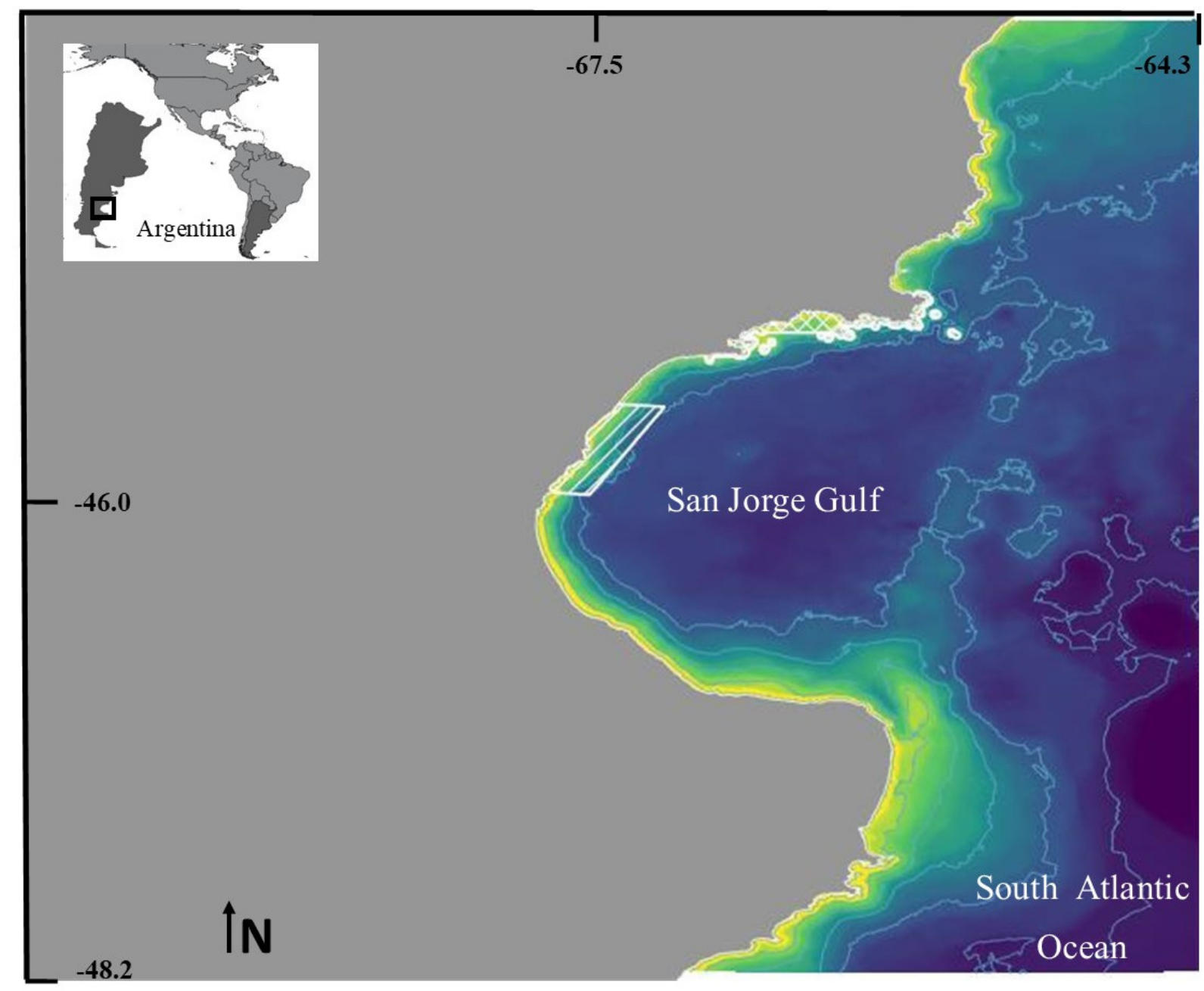

Figure 1: Study site location in Patagonia Argentina, South Atlantic Sea. Zones marked in white are the marine protected areas (MPA) 


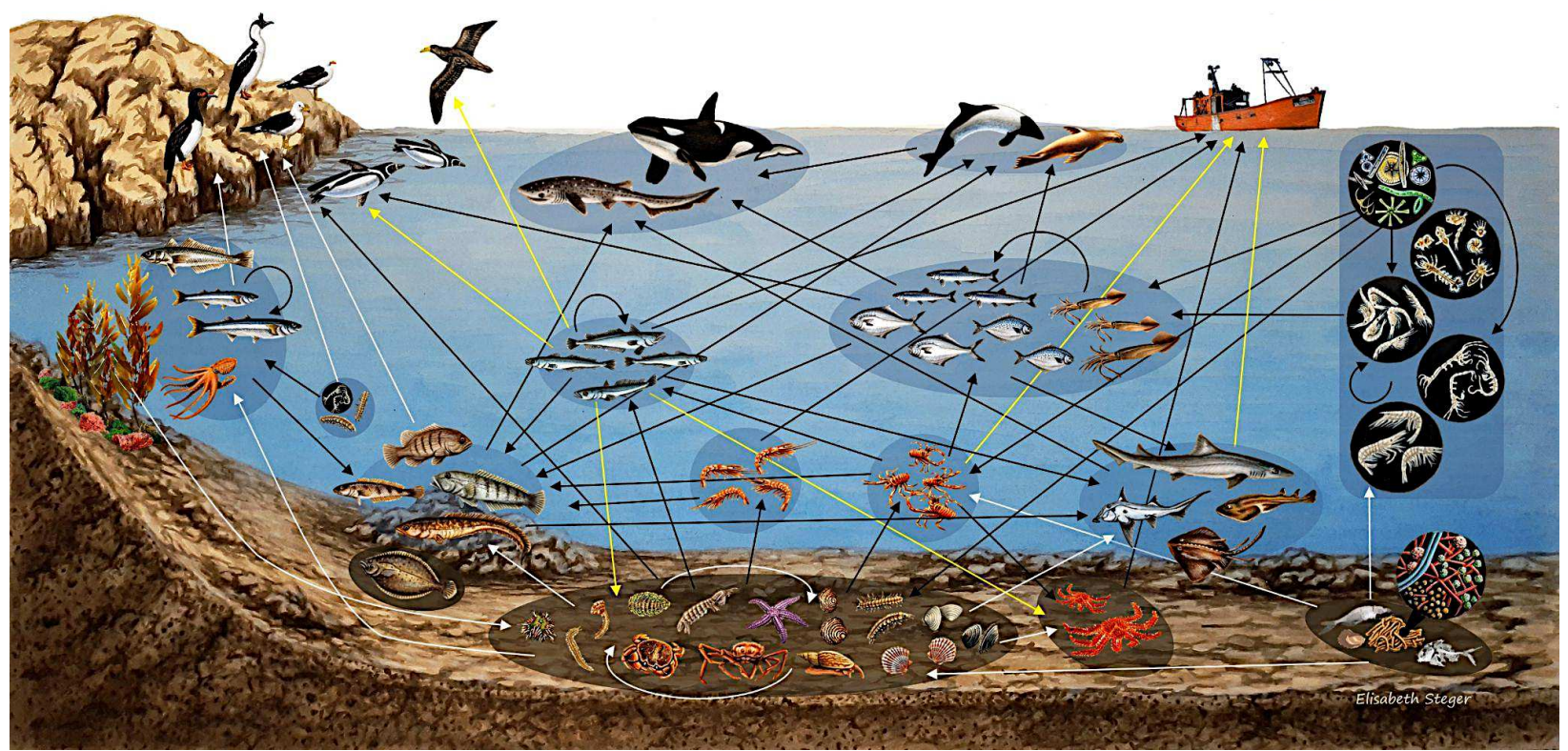

Figure 2: Simplified food web representation of the most important species in terms of the degree, relative biomass and taxon representation. Arrows represent energy and biomass fluxes direction, yellow arrows represent fluxes produced by the fishery activity (capture and discard consumption). The image was obtained with permission from. ${ }^{27}$

by trawl nets. ${ }^{30}$ For all the species in the list, an interaction was added assigning the new node "fishery" as a consumer and the species caught as a resource. To include the trophic interactions originated by discard production, discard composition was assumed to be composed only by hake, based on the major dominance of hake on discard composition. ${ }^{31}$ Then, discard consumers were identified by direct observation on fishing vessels $^{32}$ or by the presence of hake in the gut content of scavengers or opportunistic consumers. ${ }^{33-36}$

\section{(2) permission from.}

\section{Network Metrics}

To characterize the SJG food web, we used four network metrics in two versions: 1) Unweighted: only considering the existence of a trophic relationship (links), in this case, all the links count equally. 2) Weighted: we used the consumption percentage of each prey to weigh the links. The latter gives more importance to the preferred prey. The metrics were: The mean trophic level (mTL); since it was proposed as an indicator of the health of the system. ${ }^{37}$ Food webs with high mTL are supposed to be less stable ${ }^{14}$ and lower mTL means that there are fewer steps between a species and a basal resource indicating a more energy-efficient system. ${ }^{38}$ The level of Omnivory (O); defined as the percentage of nodes consuming at more than one trophic level. ${ }^{39}$ Omnivory can have either a positive or negative influence on the stability of food webs, depending on the interaction strength. High levels of omnivory are always destabilizing, intermediate levels may stabilize food webs. ${ }^{40}$ Omnivory is likely to persist at intermediate productivity levels and be more common in 
disturbed environments. ${ }^{13}$ The modularity $(\mathrm{M})$ is the degree to which a subgroup of species interact more with themselves than with the rest of the nodes. ${ }^{15,41}$ Higher levels of modularity presume higher stability, because the compartmentalization prevents disturbances from spreading but it was proved beneficial only for perturbed ecosystems. We calculated the best compartment partition using a stochastic algorithm based on simulated annealing that allows maximizing modularity for directed and weighted networks without getting trapped in local maxima configurations. ${ }^{42}$

Finally, we calculated the Quasi sign-stability (QSS) index, which is the proportion of stable networks using 10000 randomized Jacobians and keeping the predator prey structure fixed. ${ }^{43}$ The formulas for the two versions of the metrics are explained in the supplementary methods.

\section{Analysis}

Food web metrics were estimated for both food webs (with and without fishing activity) in order to assess their differences. Considering the equilibrium as the capacity of a system to return to initial conditions after a disturbance, it is expected that all network metrics respond to a more equilibrate state in the non-fishing model than in the fishing model. For the comparison we performed 1000 randomizations (except for QSS, see above) using the curveball algorithm which maintains constant the number of prey and predators for each species, therefore keeping fixed the number of columns and rows in the adjacency matrix. ${ }^{44}$ In the case of the weighted metrics additionally the values of weights (diets) were randomized maintaining the column sum fixed on the weighted adjacency matrix (See formulas on the supplementary material). The distribution of the metrics were compared between the fished and non-fishing model using Anderson-Darling test ${ }^{45}$ and the effect size; obtained by dividing the median of the data by the pooled standard deviation. The effect size interpretation is arbitrary ${ }^{46}$ so we use it as a relative measure of the magnitude of differences between food webs' metrics. Quasi sign-stability values were compared using a Chi-squared test.

All estimations were performed in $\mathrm{R}$ software, using the packages igraph, NetIndices, and Multiweb package. ${ }^{47}$ The source code and data is available at https://github.com/EcoComplex/NetworkGolfoSanJorge and Zenodo.

Table 1: Degree values (i.e. number of total interaction of each node) for the top 20 species and trophoespecies of the system from the non-fishing scenario and from the fishing food webs.

\begin{tabular}{lll}
\hline Species or trophospecies & Fishing & non-fishing \\
\hline Merluccius hubbsi & 59 & 34 \\
Pleoticus muelleri & 58 & 56
\end{tabular}




\begin{tabular}{lll}
\hline Species or trophospecies & Fishing & non-fishing \\
\hline Munida gregaria & 57 & 55 \\
Illex argentinus & 48 & 47 \\
Amphipoda & 47 & 47 \\
FISHERY & 47 & - \\
Polychaeta & 45 & 45 \\
isopods & 38 & 38 \\
Zearaja chilensis & 38 & 37 \\
Engraulis anchoita & 37 & 36 \\
Octopus tehuelchus & 37 & 36 \\
Pseudopercis semifasciata & 35 & 34 \\
detritus & 34 & 34 \\
Mustelus schmitti & 32 & 31 \\
Enteroctopus megalocyathus & 30 & 30 \\
Bathyraja spp & 29 & 27 \\
\hline Patagonotothen spp & 28 & 26 \\
\hline
\end{tabular}

132

\section{Results}

The non-fishing food web contained 165 trophic nodes, from which 115 were species and 50 were trophospecies. Nodes were connected by 1013 trophic links (Supplementary figure S2). The percentage of top predators was $16 \%$, intermediate species $78 \%$ and basal species $6 \%$. The network presented almost five trophic levels, considering the top predator Orcinus Orca with the maximum trophic level of 4.9, closely followed by Notorynchus cepedianus and Mirounga leonina (Supplementary figure S2, and supplementary table S1). The 

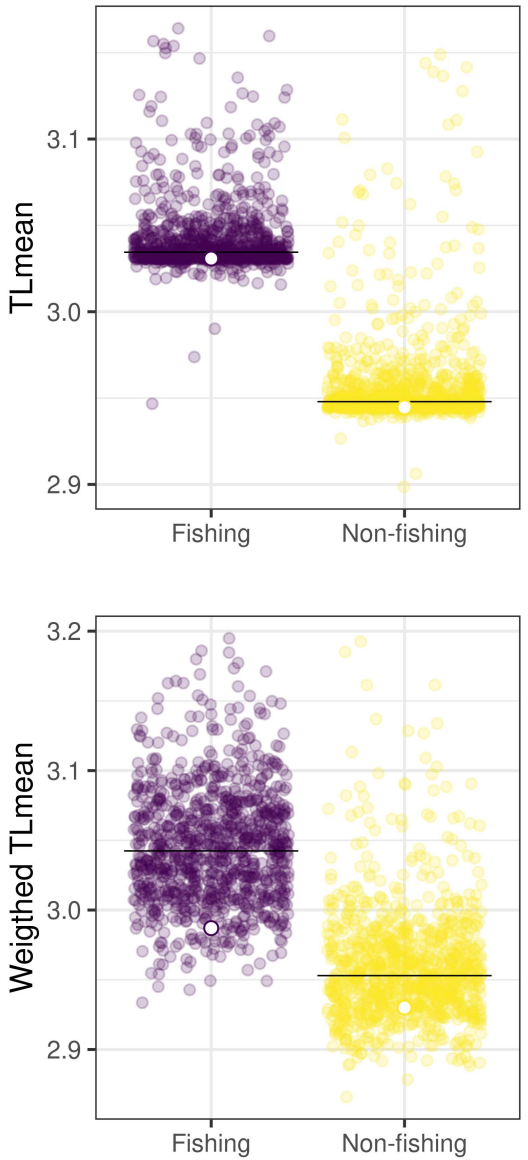
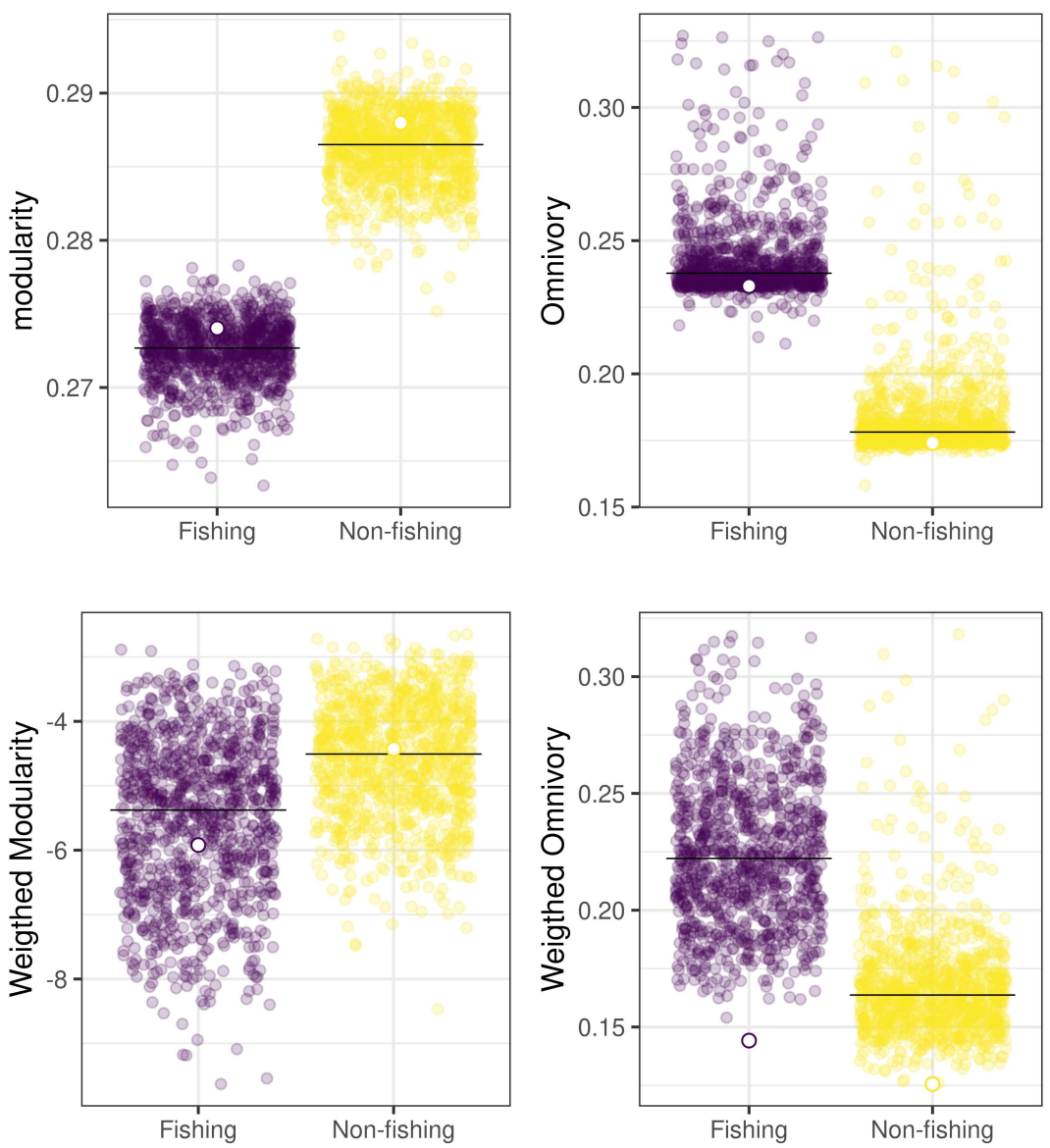

Figure 3: Comparison of the metrics for food-webs under fishing and non-fishing scenarios. The coloured points are randomizations of each food web keeping the number of links of each trophospecies constant, the weighted versions take into account the diets of the predators as link weight. The blank dots are the values of the empiric food webs, and the black lines the median of the randomized webs. Extreme values were eliminated from the plots for better visualization.

top three more connected nodes were the Argentine red shrimp, the squat lobster Munida gregaria, the Argentine squid and, with the same degree, Amphipoda grouped as trophospecies (Supplementary figure S2 and Table 1). These nodes were all crustaceans, located in the middle of the trophic network in terms of trophic level (3, 2.5, 3.6 and 2 respectively). The mean trophic level of the system was 2.9. 

predators, respectively (Table 1; Supplementary table S1). The more connected species was different from the non-fishing model, being the hake in the first place, the shrimp in the second and the squat lobster in third place (Table 1). These species were also located in the middle of the network in terms of trophic levels: $3.7,3.1,2.7$, respectively. The mean trophic level of the fished network was 3.0. 
Table 2: Omnivory level, mean trophic level (TL) and modularity values of the fishing and non-fishing model. For each metric, the median difference (median Diff), pooled standard deviation and the magnitude of the effect size, estimated as the median difference over the pooled sd.

\begin{tabular}{lllllll}
\hline Type & metric & Fishing Median & non-fishing Median & Median difference & Pooled sd & Effect Size \\
\hline Unweighted & TL & 3.0351 & 2.9482 & -0.0869 & 0.1146 & -0.7582 \\
& Omnivory & 0.2381 & 0.1784 & -0.0597 & 0.2268 & -0.2633 \\
& Modularity & 0.2727 & 0.2865 & 0.0138 & 0.0072 & 1.9072 \\
Weighted & TL & 3.0445 & 2.9534 & -0.0911 & 0.2491 & -0.3659 \\
& Omnivory & 0.2235 & 0.1639 & -0.0595 & 1.1041 & -0.0539 \\
& Modularity & -5.3772 & -4.5076 & 0.8696 & 1.1809 & 0.7363 \\
\hline
\end{tabular}

There are significant differences between the fishing and the non-fishing food webs topological metrics (mean trophic level, modularity and omnivory coefficient: Anderson Darling test $p=0.00)$. The biggest effect size in absolute value was observed for modularity and the smallest, for omnivory (Table 2, Figure 3 ). In terms of stability, the fishing food web was less stable than the non-fishing (Quasi sign-stability $p<2.2 \mathrm{e}-16$, Figure 4 ). The results for the diet weighted metrics were similar to the previous ones: all differences were significant and the effect sizes had the same ordering but were in general smaller than the unweighted ones. Regarding QSS, the differences between food webs were bigger than for the unweighted. Notice that only for the weighted omnivory, empirical food webs values fall outside of the range of the null model values (Figure 3), probably due to the randomization of predators diet. The weighted modularity was negative indicating that the link weights between the modules are larger than the weights inside the modules.

\section{Discussion}

We found that fishery activities in the San Jorge Gulf (SJG) reduced the stability of the food web. Recent results suggest that unweighted topological metrics can not detect neither alterations in fluxes ${ }^{48}$ nor changes in stability. ${ }^{19}$ In our study, both the weighted and unweighted metrics gave the same pattern, with quasi-sign stability being the metric with the most straightforward interpretation that showed the lowering of stability. Moreover, the present study constitutes the first attempt to construct a high-resolved food web of the SJG ecosystem. We collected detailed information for several low, medium and high trophic level species, which resulted in a speciose food web between the most resolved ones. ${ }^{49}$ SJG is a key feeding, reproductive and 


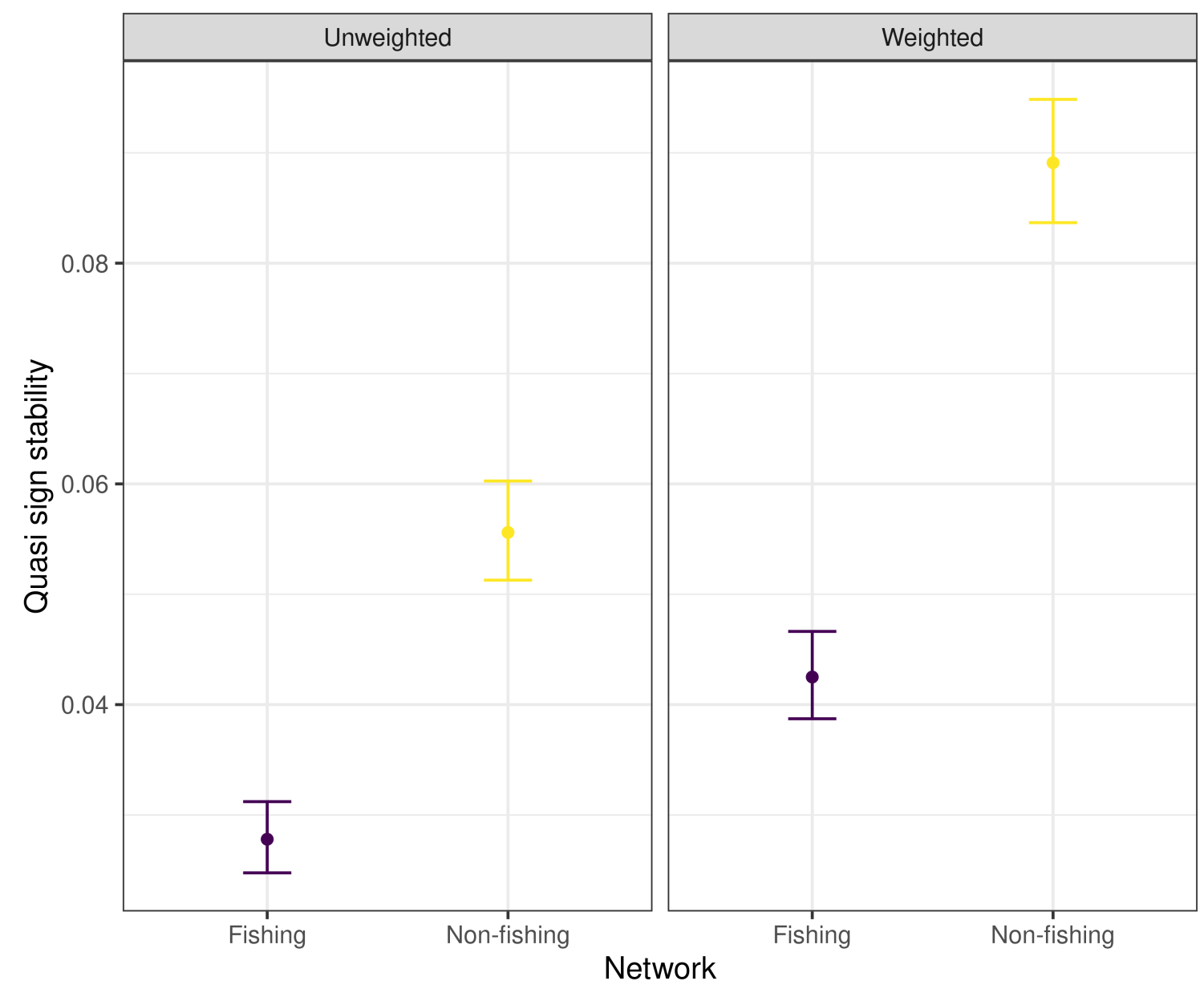

Figure 4: Quasi Sign Stability (QSS) values of the fishing and non-fishing food webs. QSS is a measure of the capacity of the system to return to equilibrium after a perturbation, the lower it is the less capacity the system has. Unweighted values consider only the topological structure of the food web, the weighted values take into account the diets of the species. Values are presented with their standard deviation. 
nursing area for the main lucrative fisheries in Argentina. The description of our network exposes the possible flows of matter and energy in the studied system, which is considered a fundamental requirement in the Ecosystem Approach of fisheries (Ecosystem Principles Advisory Panel, 1999).

The food web of SJG is a complex system with more than a hundred species and almost five trophic levels. It has several top predator populations which include many colonies of marine mammals; sea elephants, sea lions, dolphins, orcas, and also marine birds and sharks. The importance of top predators is given by their trophic function, and their loss affects the uniqueness of the system. ${ }^{50}$ Diverse top predators populations are not frequently found in other coastal systems [Agnetta2019] and their depletion is a common consequence of overexploitation. ${ }^{51-53}$ In SJG several protected areas were built to protect top predator colonies (Figure $2)^{21}$ and some populations were reported to be increasing in number ${ }^{54-56}$. Other top predator populations like sharks have no formal protection and its populations were reported to be decreasing. ${ }^{57}$

The SJG food web was previously described using two distinct approaches: stable isotope analysis ${ }^{58}$ and an Ecopath modelling. ${ }^{59}$ Our results using a network approach match several results from these previous descriptions: the length of the food web (i.e. maximum trophic levels) and trophic level values of the most abundant nodes. For example: the maximum trophic level described using stable isotope analysis was 4.7 for Parona signata ${ }^{58}$ and through Ecopath was 4.5 for the cetaceans, ${ }^{59}$ we found these species had trophic levels of 4 and 4.4, respectively. Trophic levels of important species such anchovy Engraulis anchoita (3.1), shrimp Pleoticus muelleri (3.08) and squat lobster Munida gregaria (2.6) were similar to what was reported by Gaitan ${ }^{58}\left(2.9,3.4,3.1\right.$, respectively) and Sanchez ${ }^{59}(3.2,2.6,2.2$, respectively). Also, trophic levels values match values estimated using stable isotope analysis in particular studies of the area (e.g.: the squat lobster: 2.5 in Funes, ${ }^{60}$ Acanthistius patachonicus: 3.8 and 3.9 in Funes $^{7}$ ).

In terms of degree, the network was primarily dominated by medium trophic level crustaceans, the shrimp, the squat lobster, and amphipods. The three trophic species are also dominant in abundance ${ }^{61-63}$ and are common prey to almost all fishes on the network. ${ }^{63-65}$ The current importance of the squat lobster in the system $^{61}$ does not match the description of the system performed 30 years ago,${ }^{64}$ and this change was reported for the entire area. ${ }^{66,67}$ The squat lobster occurs in pelagic and benthic ecotypes, and in both environments it is important in terms of biomass. ${ }^{67,68}$ Each ecotype feeds in the environment where it inhabits; pelagic forms feed on pelagic primary producers and benthic forms in benthic animals. ${ }^{60}$ The squat lobster captures energy and biomass from both environments and being a key prey item, could be the main energy flux between the base and the top of the system, connecting primary producers directly to top predators. Such phenomena shortens the effective size of the web and turns more efficiently the energetic fluxes throughout the web. ${ }^{67,69}$ 
In the fishing food web, the hake Merluccius hubbsi showed the higher values of degree, seconded by the shrimp and the squat lobster. This not only puts in perspective the real importance of the hake on the environment but it is itself an evidence of the impacts of fishery: enhancing the availability of the hake as prey for more trophic guilds and levels. The consequences of this phenomena are mainly reflected on the level of omnivory and the changes on stability of the system, and the changes on energy fluxes.

The level of omnivory was already high in the non-fishing system compared to other marine systems ${ }^{49,70}$ and increased in the fished system. This is a consequence both of fishery consuming resources from different trophic levels ${ }^{71}$ and of the discard consumption $\left[{ }^{72}\right)$. There is a current debate on whether omnivory favours or not stability, the latest studies indicate that strong omnivory levels could destabilize trophic networks, whereas weak to moderate strength levels of omnivory can confer stability to food webs. ${ }^{73}$ The effect of modularity is to buffer the effect of perturbations, with a stronger effect when the system is more complex and is subject to perturbations. ${ }^{74}$ In this study, the fishing food web presented higher levels of omnivory accompanied with lower levels of modularity, both things points out towards a lower level of stability that is supported by the Quasi sign-stability difference between networks.

The hake is the most abundant species in the food web and is a highly connected, the change observed on hake's degree (from $\mathrm{N}^{\circ} 12$ to $\mathrm{N}^{\circ} 1$ on the fishing food web) suggests that it could have a major impact on the system. This change can potentially spread perturbations through the food web by transmitting abundance alterations to a great number of nodes. ${ }^{75}$ Specifically in an ecosystem as the SJG with low functional diversity where each ecological role is covered by one or a few species, and the loss of a species compromises its ecological function. ${ }^{22}$ However, hake increased its degree in the fishing food web not by direct predation but by its consumption once discarded. As discarding is an undesirable practice that is expected to tend to be reduced over time, the effects of the fishery on the structure of the food web can be reduced by improving fishing practices.

The inclusion of the fishery node and the availability of discard should produce a re-configuration of energy fluxes. Many changes have been reported from the beginning of fishery exploitation, 40 years ago, For example, a decrease in the size of landed hake of the southern stock between 1990 and $2013,{ }^{76}$ a decrease in the abundance of Acanthistius patachonicus, Genypterus blacodes, Zearaja chilensis, Psamobatis spp and Sympterygia spp in the catch of scientific surveys between 2005 and 2014, ${ }^{77}$ and the recent increase in abundance of Munida gregaria ${ }^{67,68}$ that is also a connected species (a common prey). Thus ,all these changes reflect an important modification of energy fluxes likely produced by the fishery, we were unable to quantify these changes but all the network metrics imply a decrease in stability that in turn suggest the system could change its state, and influence the ecosystem functioning. 
It is probable that our results are underestimating the effects of fishery exploitation on the ecosystem because only the topology and species diets are addressed, and the actual changes in the food web of SJG would be greater (mainly taking into account also species biomasses). However, our results were capable of showing how human activity can alter the structure, the stability, and energy fluxes of an ecosystem. This study took place in a relatively recently exploited area, compared to the Mediterranean, the North Atlantic or several fisheries of the Pacific, and therefore it maintains many "original" interactions worth to be described, understood and acknowledged before the system undergoes further changes.

\section{Declarations of Competing Interest}

All authors declare no conflict of interest.

\section{Author contribution}

FM: Investigation, data collection, methodology, writing. SL: methodology, software, data analysis, visualization, writing, revision. CGF: Conceptualization, data analysis, revision. IOO: Supervision, revision, feedback. GDE: Idea, conceptualization, supervision, writing, revision.

\section{Acknowledgments}

We would like to thank Pablo Yorio for his feedback as a key expert of San Jorge Gulf, his recommendations and contributions on this paper. Several other experts also contributed with their criteria to revise the reconstruction, such as Damián Vales, Nicolás Ortiz, Gregorio Biggatti, Maria Martha Pitu Mendez.

\section{Data availability}

The source code and data is available at zenodo and Github https://github.com/EcoComplex/NetworkGol foSanJorge.

\section{Bibliography}

1. Pauly, D. Anecdotes and the shifting baseline syndrome of fisheries. Trends in Ecology $\&$ Evolution 10, 430 (1995).

2. $\quad$ Meeting the sustainable development goals. (2018). 
3. Teh, L. C. L. \& Sumaila, U. R. Contribution of marine fisheries to worldwide employment. Fish and Fisheries 14, 77-88 (2013).

4. Halpern, B. S., Selkoe, K. A., Micheli, F. \& Kappel, C. V. Evaluating and Ranking the Vulnerability of Global Marine Ecosystems to Anthropogenic Threats. Conservation Biology 21, 1301-1315 (2007).

5. Kaiser, M. J., Collie, J. S., Hall, S. J., Jennings, S. \& Poiner, I. R. Modification of marine habitats by trawling activities: Prognosis and solutions. Fish and Fisheries 3, 114-136 (2002).

6. Hiddink, J. G. et al. Selection of indicators for assessing and managing the impacts of bottom trawling on seabed habitats. Journal of Applied Ecology 57, 1199-1209 (2020).

7. Funes, M., Marinao, C. \& Galván, D. E. Does trawl fisheries affect the diet of fishes? A stable isotope analysis approach. Isotopes in Environmental and Health Studies 0, 1-17 (2019).

8. Preciado, I. et al. Small-scale spatial variations of trawling impact on food web structure. Ecological Indicators 98, 442-452 (2019).

9. $\mathrm{Su}, \mathrm{L}$. et al. Decadal-Scale Variation in Mean Trophic Level in Beibu Gulf Based on Bottom-Trawl Survey Data. Marine and Coastal Fisheries 13, 174-182 (2021).

10. Jennings, S., van Hal, R., Hiddink, J. G. \& Maxwell, T. A. D. Fishing effects on energy use by North Sea fishes. Journal of Sea Research 60, 74-88 (2008).

11. Ruiter, P. C. de, Neutel, A.-M. \& Moore, J. C. Energetics, Patterns of Interaction Strengths, and Stability in Real Ecosystems. Science 269, 1257-1260 (1995).

12. Bascompte, J. Disentangling the Web of Life. Science 325, 416-419 (2009).

13. Wootton, K. L. Omnivory and stability in freshwater habitats: Does theory match reality? Freshwater Biology 62, 821-832 (2017).

14. Borrelli, J. J. \& Ginzburg, L. R. Why there are so few trophic levels: Selection against instability explains the pattern. Food Webs 1, 10-17 (2014).

15. Stouffer, D. B. \& Bascompte, J. Compartmentalization increases food-web persistence. Proceedings of the National Academy of Sciences of the United States of America 108, 3648-52 (2011). 
16. Márquez-Velásquez, V., Raimundo, R. L. G., de Souza Rosa, R. \& Navia, A. F. The Use of Ecological Networks as Tools for Understanding and Conserving Marine Biodiversity. in Marine Coastal Ecosystems Modelling and Conservation: Latin American Experiences (eds. Ortiz, M. \& Jordán, F.) 179-202 (Springer International Publishing, 2021). doi:10.1007/978-3-030-58211-1_9.

17. Neutel, A.-M. \& Thorne, M. A. S. Interaction strengths in balanced carbon cycles and the absence of a relation between ecosystem complexity and stability. Ecology Letters 17, 651-661 (2014).

18. Neutel, A.-M. \& Thorne, M. A. S. Beyond connectedness: Why pairwise metrics cannot capture community stability. Ecology and Evolution 6, 7199-7206 (2016).

19. Saravia, L. A., Marina, T. I., Kristensen, N. P., De Troch, M. \& Momo, F. R. Ecological network assembly: How the regional metaweb influences local food webs. Journal of Animal Ecology n/a, (2021).

20. Góngora, M. E., González-Zevallos, D., Pettovello, A. \& Mendía, L. Caracterización de las principales pesquerías del golfo San Jorge Patagonia, Argentina. Latin american journal of aquatic research 40, $1-11(2012)$.

21. Yorio, P. Marine protected areas, spatial scales, and governance: Implications for the conservation of breeding seabirds. Conservation Letters 2, 171-178 (2009).

22. Rincón-Díaz, M. P., Bovcon, N. D., Cochia, P. D., Góngora, M. E. \& Galván, D. E. Fish functional diversity as an indicator of resilience to industrial fishing in Patagonia Argentina. Journal of Fish Biology 99, 1650-1667 (2021).

23. González-Zevallos, D. \& Yorio, P. Consumption of discards and interactions between Black-browed Albatrosses (Thalassarche melanophrys) and Kelp Gulls (Larus dominicanus) at trawl fisheries in Golfo San Jorge, Argentina. J Ornithol 152, 827-838 (2011).

24. Vinuesa, J. H. \& Varisco, M. Trophic ecology of the lobster krill Munida gregaria in San Jorge Gulf, Argentina. Investigaciones marinas 35, 25-34 (2007).

25. Belleggia, M. et al. Trophic ecology of yellownose skate Zearaja chilensis, a top predator in the south-western Atlantic Ocean. J Fish Biol 88, 1070-1087 (2016). 
26. Pasti, A. T. et al. The diet of Mustelus schmitti in areas with and without commercial bottom trawling (Central Patagonia, Southwestern Atlantic): Is it evidence of trophic interaction with the Patagonian shrimp fishery? Food Webs 29, e00214 (2021).

27. Dans, S. et al. El golfo san jorge como área prioritaria de investigación, manejo y conservación en el marco de la iniciativa pampa azul. Revista Ciencia e Investigación 71, 21-43 (2021).

28. de la Garza, J. M., Bartozzetti, J. \& Boccanfuso, J. Campaña de langostino patagónico. Informe de Campaña. (2010).

29. de la Garza, J. M., Cucchi Colleoni, D. \& Izzo, A. Campaña de relevamiento de langostino patagónico en el golfo San Jorge a bordo de un buque comercial. Informe de Campaña. (2011).

30. de la Garza, J. M., Fernández, M. \& Ravalli, C. Langostino patagónico (Pleoticus muelleri). Informe de Campaña. (2013).

31. Góngora, M. E. Composition and dynamics of the incidental catch in the Patagonian shrimp (Pleticus muelleri) fishery. (Universidad Nacional del Comahue, Centro Regional Universitario Bariloche, 2011).

32. González Zevallos, D. R., Marinao, C. \& Yorio, P. M. Importancia De Los Descartes Pesqueros En La Dieta De La Gaviota Cocinera (larus Dominicanus) En El Golfo San Jorge, Patagonia. Ornitología Neotropical 28, 103-111 (2017).

33. Crespo, E. A. et al. Direct and Indirect Effects of the Highseas Fisheries on the Marine Mammal Populations in the Northern and Central Patagonian Coast. J. Northw. Atl. Fish. Sci. 22, 189-207 (1997).

34. Gandini, P. A., Frere, E., Pettovello, A. D. \& Cedrola, P. V. Interaction between Magellanic Penguins and Shrimp Fisheries in Patagonia, Argentina. The Condor 101, 783-789 (1999).

35. Tschopp, A., Cristiani, F., García, N. A., Crespo, E. A. \& Coscarella, M. A. Trophic niche partitioning of five skate species of genus Bathyraja in northern and central Patagonia, Argentina. J Fish Biol 97, 656-667 (2020).

36. Kasinsky, T., Yorio, P., Dell'Arciprete, P., Marinao, C. \& Suárez, N. Geographical differences in sexspecific foraging behaviour and diet during the breeding season in the opportunistic Kelp Gull (Larus dominicanus). Mar Biol 168, 14 (2021). 
37. Pauly, D., Watson, R. \& Alder, J. Global trends in world fisheries: Impacts on marine ecosystems and food security. Phil. Trans. R. Soc. B 360, 5-12 (2005).

38. Olivier, P. et al. Exploring the temporal variability of a food web using long-term biomonitoring data. Ecography 42, 2107-2121 (2019).

39. Bersier, L.-F., Banašek-Richter, C. \& Cattin, M.-F. Quantitative Descriptors of Food-Web Matrices. Ecology 83, 2394-2407 (2002).

40. Gellner, G. \& McCann, K. Reconciling the Omnivory-Stability Debate. The American Naturalist 179, 22-37 (2012).

41. Newman, M. E. J. \& Girvan, M. Finding and evaluating community structure in networks. Phys. Rev. E 69, 26113 (2004).

42. Reichardt, J. \& Bornholdt, S. Statistical mechanics of community detection. Phys. Rev. E 74, 16110 (2006).

43. Allesina, S. \& Pascual, M. Network structure, predator-prey modules, and stability in large food webs. Theor Ecol 1, 55-64 (2008).

44. Strona, G., Nappo, D., Boccacci, F., Fattorini, S. \& San-Miguel-Ayanz, J. A fast and unbiased procedure to randomize ecological binary matrices with fixed row and column totals. Nature Communications 5, 4114 (2014).

45. Scholz, F. W. \& Stephens, M. A. K-Sample Anderson-Darling Tests. Journal of the American Statistical Association 82, 918-924 (1987).

46. Lakens, D. Calculating and reporting effect sizes to facilitate cumulative science: A practical primer for t-tests and ANOVAs. Frontiers in Psychology 4, 863 (2013).

47. Saravia, L. A. Multiweb: An R Package for multiple interaction ecological networks. (Zenodo, 2019). doi:10.5281/zenodo.3370397.

48. Kortsch, S. et al. Disentangling temporal food web dynamics facilitates understanding of ecosystem functioning. Journal of Animal Ecology n/a, (2021).

49. Marina, T. I. et al. Architecture of marine food webs: To be or not be a "small-world". PLoS ONE 13, 1-13 (2018). 
50. Navia, A. F., Cruz-Escalona, V. H., Giraldo, A. \& Barausse, A. The structure of a marine tropical food web, and its implications for ecosystem-based fisheries management. Ecological Modelling 328, 23-33 (2016).

51. Baum, J. K. et al. Collapse and Conservation of Shark Populations in the Northwest Atlantic. Science (2003) doi:10.1126/science.1079777.

52. Bearzi, G. et al. Overfishing and the disappearance of short-beaked common dolphins from western Greece. Endangered Species Research 5, 1-12 (2008).

53. Lotze, H. K., Coll, M., Magera, A. M., Ward-Paige, C. \& Airoldi, L. Recovery of marine animal populations and ecosystems. Trends in Ecology $\&$ Evolution 26, 595-605 (2011).

54. Reyes, L. M. Cetaceans of Central Patagonia, Argentina. aquatic mammals 32, 20-30 (2006).

55. Lisnizer, N., Garcia-Borboroglu, P. \& Yorio, P. Spatial and temporal variation in population trends of Kelp Gulls in northern Patagonia, Argentina. Emu - Austral Ornithology 111, 259-267 (2011).

56. Yorio, P. et al. Population trends of Imperial Cormorants (Leucocarbo atriceps) in northern coastal Argentine Patagonia over 26 years. Emu - Austral Ornithology 120, 114-122 (2020).

57. Irigoyen, A. \& Trobbiani, G. Depletion of trophy large-sized sharks populations of the Argentinean coast, south-western Atlantic: Insights from fishers' knowledge. Neotrop. ichthyol. 14, (2016).

58. Gaitán, E. N. Tramas tróficas en sistemas frontales del Mar Argentino: estructura, dinámica y complejidad analizada mediante isótopos estables. (Universidad Nacional de Mar del Plata, Facultad de Ciencias Exactas y Naturales., 2012).

59. Sanchez, M. F. et al. Caracterización ecológica del Golfo San Jorge (Argentina) mediante modelación ecotrófica multiespecífica. 30 https://www.inidep.edu.ar/wordpress/?page_id=1959 (2009).

60. Funes, M., Irigoyen, A. J., Trobbiani, G. A. \& Galván, D. E. Stable isotopes reveal different dependencies on benthic and pelagic pathways between Munida gregaria ecotypes. Food Webs 17, e00101 (2018).

61. Belleggia, M. et al. Are hakes truly opportunistic feeders? A case of prey selection by the Argentine hake Merluccius hubbsi off southwestern Atlantic. Fisheries Research 214, 166-174 (2019). 
62. Roux, A., Piñero, R., Moriondo, P. \& Fernández, M. Diet of the red shrimp Pleoticus muelleri (Bate, 1888) in Patagonian fishing grounds, Argentine. Revista de Biología Marina y Oceanografía 44, (2009).

63. de la Garza, J. et al. An overview of the argentine red shrimp (Pleoticus muelleri, Decapoda, Solenoceridae) fishery in Argentina : biology, fishing, management and ecological interactions. (Instituto Nacional de Investigación y Desarrollo Pesquero (INIDEP), 2017).

64. Sánchez, M. F. \& Prenski, L. B. Ecología trófica de peces demersales en el Golfo San Jorge. Trophic ecology of demersal fish from San Jorge Gulf 10, 57-71 (1996).

65. Copello, S., Quintana, F. \& Pérez, F. Diet of the southern giant petrel in Patagonia: Fishery-related items and natural prey. Endangered Species Research 6, 15-23 (2008).

66. Alonso, R. B. et al. The opportunistic sense: The diet of Argentine hake Merluccius hubbsi reflects changes in prey availability. Regional Studies in Marine Science 27, 100540 (2019).

67. Diez, M. J., Cabreira, A. G., Madirolas, A. \& Lovrich, G. A. Hydroacoustical evidence of the expansion of pelagic swarms of Munida gregaria (Decapoda, Munididae) in the Beagle Channel and the Argentine Patagonian Shelf, and its relationship with habitat features. Journal of Sea Research 114, 1-12 (2016).

68. Ravalli, C., De La Garza, J. \& Greco, L. L. Distribución de los morfotipos gregaria y subrugosa de la langostilla Munida gregaria (Decapoda, Galatheidae) en el Golfo San Jorge en la campaña de verano AE-01/2011. Integración de resultados con las campañas 2009 y 2010. Rev. Invest. Desarr. Pesq. 22, 29-41 (2013).

69. Lovrich, G. A. \& Thiel, M. Ecology, physiology, feeding and trophic role of squat lobsters. The Biology of Squat Lobsters (Csiro Publishing, 2011).

70. Link, J. Does food web theory work for marine ecosystems? Marine Ecology Progress Series 230, 1-9 (2002).

71. Bieg, C. et al. Linking humans to food webs: A framework for the classification of global fisheries. Frontiers in Ecology and the Environment 16, 412-420 (2018).

72. Shephard, S. et al. Scavenging on trawled seabeds can modify trophic size structure of bottom-dwelling fish. ICES Journal of Marine Science 71, 398-405 (2014). 
73. Kratina, P., Greig, H. S., Thompson, P. L., Carvalho-Pereira, T. S. A. \& Shurin, J. B. Warming modifies trophic cascades and eutrophication in experimental freshwater communities. Ecology 93, 1421-1430 (2012).

74. Gilarranz, L. J., Rayfield, B., Liñán-Cembrano, G., Bascompte, J. \& Gonzalez, A. Effects of network modularity on the spread of perturbation impact in experimental metapopulations. Science 357, 199 LP-201 (2017).

75. Pérez-Matus, A. et al. Temperate rocky subtidal reef community reveals human impacts across the entire food web. Marine Ecology Progress Series 567, 1-16 (2017).

76. Santos, B. \& Villarino, M. F. Evaluación del estado de explotación del efectivo sur de 41 S de la merluza ( Merluccius hubbsi) y estimación de la captura biológicamente aceptable para 2014. 1-30 $(2013)$.

77. Belleggia, M., Giberto, D. \& Bremec, C. Adaptation of diet in a changed environment: Increased consumption of lobster krill Munida gregaria (Fabricius, 1793) by Argentine hake. Marine Ecology 38, e12445 (2017). 


\section{Supplementary Files}

This is a list of supplementary files associated with this preprint. Click to download.

- Appendices.pdf 